Post.mortem Rremination.

The sudden traglo end led me to expect to find a cerebral abscess ruptured into the ventricle, but all that was revesled was meningitis.

REMARKS.

Ballance says that when the following group of symptoms are present together septic thrombosis is certainly present:

1. A history of puralent aural discharge for a year or more 2. Sudden onset of the lliness, with headeshe, vomiting, rigor, and pain in the affocted ear.

3. An oscillating temperature.

4. Vomiting, repeated day by day.

5. A second, third, or more rigors.

6. Locsl tenderness and oedema over the mastold or in the cjurse of the jugular vein.

7. Stiffness of the muscles of the back or slde of the neck.

8. Optic neuritis.

Schlatter further says that janndice is a frequent sgmptom, and that the liver and spleen are always enlarged.

There can be little doubt that if all the above symptoms were present In one case, a surgeon who had never seen a patlent snffering from sinns thrombosis would have no difficalty in diagnosing it, but what chance could he expect to have of a successful result on having recourse to operation? In order to save the llfe of the patient it is essential that the operation should be done as early as possible; If one waits day after day to observe repeated rigors and vomitings time is allowed for general pyaemla to be established. Practically, however, the diagnosis is not as easy as it would seem by the reading of textbooks, as the cases are commonly pre ceded and accompanled by mastold disease, and may be compllcated, too, by the coexlatence of menlngitls or cerebral abscess, so that the overlapping of symptoms makes diagnosis often a difficult matter.

In the second of the above-mentioned cases a diagnosis was easlly made, although there had been no rigor or vomlting; the desfness and the history of an aural discharge, together with the sudden rise of temperature and development of tenderness and oedems in the neck, rendered it imperative that the slnus should be opened, especlally, too, as the mastold had not been operated on.

In the first case, I should have been better advised if I had explored the sinus first, as the boy on admission had fluld In one knee-joint, and although he had no great rise In temperature he looked very 111 ; and when the mastold was first opened only a little sanious fluld was obtalned. Later on I was disinclined to open his sinus, having an Infected mastold cavity so near to it, nntll I felt sure of the existence of the olnus thrombosis; so that by waltIng until the child had a rigor valuable time was lost. Fortunately for the patlent, the delay did not cost him his llfe, but there is no doubt that it greatly prolonged hls Illness.

In the second case, I regretted cutting off the 2 in. of the jugular veln, as it would have been better to have left thils hanging out of the upper part of the wound so that it could discharge into an isolated dressing; in this way infection of the long wound in the neck might have been prevented, and the reopening of it rendered unnecessary. Indeed, In another case. I should feel disposed, even il the blood were flaid in the veln in the neok, to divide the jugular fairly low down, and then bring it out into the dressing, and in order to keep it patent to insert a rubber tube into it. In this way the jugular forsa would be more efficlently drained. Mr. Ballance (Lancet, 1904) says that removal of the vein is better than ligature, but, however high up it may be tled, there will be a little pocket left to hold pus, which wlll not be so easlly drained through the sinus as it would il there were an open vein left through which the sinus could be Irrigated.

Although this patient unfortunately died, the case must be regarded as anccessfal so far as the treatment of the sinus Infection was concerned. The death was due to meningitis.

The Fifth. Pan-American Medical Congress will take place in Guatemala, C.A., this year from August 5 th to 8 th. UNDER the will of the late Mr. Edward Aston, of Wilmslow Park, Cheshire, the "Cancer Hospital Pavilion" at Manchester. recelves a bequest of $£ 1,000$, a simllar sum geing to the Northern Counties Hospital for Incurables at Manideth.

\section{THE ETIOLOGY AND TREATMENT OF ECZEMA.}

Bx LEIGHTON KESTEVEN, M.R.C.S.ENG., MULLOMBIMBY, N.S.W.

Observation goes to prove that eczems is a pure neuropathla, and that to regard it solely as a local affection is a grave misconception calculated to lead to serlous error in treatment. The theory that eczems was the direct result of specific dyscrasla, or "blood humours," has long ince been. relegated to the limbo of obscurity. on the very self-evident fact that speclfic types of eczematous exuption do not accompany specific dyscrasia. The character of the eruption is unvarled by its aupposed origin.

But that certain pathological states are frequently the indirect factors in the causation of eczematous attacks may be accepted without cavll on the evidence of the multiform eczemata we meet accompanying or following such states. The origln, however, of such eczemats is to be attributed to neurotic actlon.

The very nature of the affection Itself-an exudative dermatitis due to capillary engorgement-indlcates clearly vasomotor disturbance due to some morbific influence on the sympathetic centres of the nervous system.

The processes of secretion and nutrition being so largely controlled by the sympathetlc, it is only rational to turn to it in the course of investigation Into the source of this troublesome affection as the probable lountain head, when we are met with multifarious instances of reflex neuroses conditional on Its Inhibitory infiuence. The eruption of urticaria is generally consequent on disturbance of the digestive functions. Urtlcaria is practically the equivalent of the Initial stage of eczema, and not infrequently develops into It. Herpes zoster appears only on the track of an angry nerve, and disappears ejnchronously with the concomitant neuralgik. Herpes Is a frequent companion of certain catarrhal affections, and the intolerable pruritus whlch so often is associated with lcterus, albuminurla, amenorrhoes, and other functional disturbances, can only be of sympathetic origln.

In the same way eczems is a common concurrent of many functlonal and nervous derangements. So often, Indeed, is it associated with gout as to tempt one to formulate "gouty eczems" as a speclfic type; but that it certainly is not, but the indirect ontcome of the Intense disturbance of the nervous system, not of the direct toxic action of the gout. Sometimes it is the precursor, sometimes the follower, of the gouty attack.

Uterine disorders bring often with them in their train the added misery of eczematous eruptions, and there are many women who are never pregnant without this afflotion. Indeed, there are some who (quoting Hebra) "during several pregnancles were attacked by eczema of the hands always at the aame perlod, so that in the later ones they could be more certain of having concelved, from the appearance of thls disease than from the cessation of the menses or the movement of the child." Disordered menstruation even will often bring on eczems of undoubtedly neurotio character.

In mental cases-especlally imbecillty-eczems is most prevalent.

It would be easy to enumerate instances in plenty in proof of the Inhibitory influence of the eympathetic gystem of nerves. Hebra himself In a half-hearted sort of way ("to prevent misunderstanding," and treating the question as one "that must be left for the solution of professed physiologists"), after deallng with all sides of it, seys :

Every case of this disease is not the result of local irritation, but may be caused by affections of the rest of the body. Eren In these instances, however, the disturbence of cutaneous circulation may be explained by the consensus nervorum, just as well as by the assumption hitherto current of the presence of some morbid produot in the blood.

Even where local irritation is the excliting cause of the attack it still remains a neurosis. External toxic applicatlons, friction, heat, and cold, and the turgescence of varicosity are only the irritants of the peripheral filaments of the sensory nerves which set the eczema golng.

Eczema may thus be divided into two classes for purposes of treatment: (1) That from within, acting through the sympathetic chain of the functional system, may. be denoted the gangllonic or Idlopathic form, and 
(2) that arising from external or local irritgtion, the peripheral or traumatic.

This classification Indicates the line which the treatment should follow with success. Though there is no drug or set of drugs whose action can be called specific in a complaint with manifestations so diverse as in this, there are a select few we can use wlth canfidence to obtain the necessary control over the neural distarbance, elther directly or indirectly, be the exciting cause what it may.

Thus, if a storm of gout has upset the sympathetic nerves, with the result of an eczematous eruption, the usual treatment for gout must be adopted, plus a direct nerve sedative. In thls instance potasslum lodide and acetanilid act well; but colchlcum should be avolded, as It dilates the capillaries and tends to Increase the exudation, whilst it often has a distinctly irritative effect upon the skin.

In eczema of an asthenic type, from ansemla, the Indication is the liberal administration of Iron with such nerve tonics as strychnine and quinine, to brace up the vasomotors. If alcohol is the Irritant, abstinence, with the bromides and atroplne, will bring speedy alleviation, the latter because of its peculiar control over the capillarles and power of checking perspiration. It must be given in small doses, however, as increased amounts paralyse the termination of the secretory nerves and relax the caplllaries. Dyspepsia, so frequently the exclting cause, calls for careful dieting, attention to the bowels, and correction of the allmentary disturbance, plus such nerve sedatlve as the bromides, in sufficient doses to arrest the gastric nerve Irritation.

The eczema that accompanies uterine trouble disappears, as a rule, with its removal, just as the eczema of pregnancy terminates with the parturition; but a nerve sedative is essential to Its immedlate relief, and chloral and belladonna are the best here.

As in the above so in all others, of whatever nature, whilat carelully devoting attention to the exciting cause, the necessary nerve sedatives must form the one chlef element in the treatment.

Local applications must be resorted to in addition, and of the thousand and one which have at different times been lauded, there are two or three only which are of aseured and permanent benefit. Analgesic action is the desideratum to meet the peripheral irritation. Nothing can compare, for the immediate and permanent relief whlch it confers, with carbolic acld if properly utillzed, but as it has hitherto been applied in almost futlle style, its real practical value has not been realized. In almost every treatlse on the subject, while it has been highly recommended $8 \mathrm{~s}$ a relief to the distressing pruritus, the strength in which it has been prescribed has rendered it useless as a curative agent. Now, carbolic acid, as demonstrated long ago by Dr, Bul, is a most powerful local anaesthetlc if used in sufficient strength, and the anaesthesla which it produces is perslstent for a longer period than any other. The burning sensation it causes at first soon passes off, lesving a palnless surface. The pure (liquid) carbolic applied to a red inflamed eczema gives oharp but short punishment and leaves the part practically dead, and this dries rapldly, forming a scab under which the prevlously raw surface heals quickly; the scab on falling off leaves the surface clean and sound. This is herolc treatment, and must be applled to only limited areas at one sitting; the pain of the application can be obviated by cocalne if the subject is sensitive, and belore the effect of the cocaine has passed off the part will be anaesthetlzed by the carbolic. For amall patches, such as appear on the hands, feet, scalp and ears, it is particularly serviceable. For general use in all eczematous eruptions at every stage the 1 in 11 solution should be used, and though it certainly smarts for a time, It gives immediate rellef to the aymptoms and rapidly checks and arrests the progress of the eruption.

Tincture of lodine also smarts somewhat, but gives great relief to the 1 tohing and burning, and lessens the infiltration. The two together make a happy combination $-\zeta_{j}$ of tinct. iodi to $\xi i x$ of the 1 in 11 carbolic solution for a lotion, to be kept applied on lint under oiled silk. In the Intertrigo which so commonly occurs between the toes and extends into the tough skin of the feet, a bath of this for the feet, Irequently repeated, gives wonderfal relief. Starch poultice makes a good vehicle for the application of this lotion, and is useful on tender surfaces, such as the face and neck, painted on.

Suprarenal extract is a good application previous to the carbolic, owing to its power of reducing the turgescence and exudation, thus leaving the surface fit for its action; whilst, applled in the very beginning of the initial erythematous istage, it will often entirely arrest it. Adrenalin is undoubtedly the best form of this substance.

Greasy applications should only be applied in the dry desquamative stage. Used in the molst stages, they only aggravate the trouble by retaining the acrid irritating exudation. This exudation should be constantly washed away with pure cold water, which should be poured very gently over the part, and all iriction avolded. Sosp, whether medicated or otherwlse, should be religiously avolded. Suprarenal added to the water greatly increases the relief it gives:

These remarks are based on observations extending over the last fifteen years, during which I have met with very considersble success in following out my deductions on the neurotic character of eczema, and I commend the treatment as worthy of trial.

\section{DIVING AND CAISSON DISEASE.}

\section{A SUMMARY OF RECENT IRVESTIGATIONS.}

By SURghon N. HOWARD MUMMERY, M.R.C.S, R N. [Communicated by the Director General, R.N.]

$\Delta$ s I belleve that the recent and most Important researches into the most interesting subject of diving have not been published in any form in the medical press which clrculates amongst members of the medical profession in general, I may, I hope, be pardoned for attempting to enumerate them in briel form, and point out that the work done at the Lister Institute by Dr. Holdane, Dr. Boycott, and Llentenant Damant, on behalf of the Speclal Committee appointed by the $\Delta$ dmiralty, has completely revolntionized both the procedure of diving and the treatment of those morbld conditions which are met with among divers, and attributable to that occupation. In H.M. navy diving operations are contlnually belng carried out for Instruction, for perlodical exerclse, and for all kinds of practical work, though seldom at greater depths than 17 fathoms, and usually at much less. Medical officers of the navy are at times called upon to treat cases of so-called calsson disease, and a knowledge of the principles and practice of diving, and also of the best way to deal with any aymptoms which may arise, is essential to them. Untll quite recently, if anything went wrong with a diver he was at once brought to the surface, and was on no account permitted to go down again on that occasion. Now, on the other hand, should a diver come np suffering from the effects of too great a depth, too long a stay below, or too rapld an ascent, he is invariably sent down again, kept there for a certaln time, and thereby cured.

When man is subject to the normal stmospheric pressure of $15 \mathrm{lb}$. to the lquare Inch, his tisanes are saturated with nitrogen at that pressure. Suppose, now that this man goes down in a diving dress to a depth of 28 tathoms; he will then be subject to the pressure at that depth-namely, $75 \mathrm{lb}$. plus the atmospheric pressure of $15 \mathrm{lb}$, making \& total of $90 \mathrm{lb}$. The tlasues, which were previonsly saturated with nitrogen at a pressure of $15 \mathrm{lb}$., will now have to become saturated at the new pressure of $90 \mathrm{lb}$., or slx times as much as before. The blood will therefore take up nitrogen from the Insplred air until that point is reached. This change that takes place in the amount of nitrogen in the tissues is called the "process of saturation" and there are three chle? factors in 1ts causstion-"atmospheric pressure," or the normal one of $15 \mathrm{lb}$; " positive pressure," or pressure in excess of atmospherlc pressure; and "absolute pressure," or the total pressure at the time belng plus atmospherlc pressure. Therefore absolnte pressure equals positive pressure plus $15 \mathrm{lb}$. The process of saturation takes place as follows: The arterial blood in the lungs takes ap nitrogen from the Insplred air, supplied by the pump, and conveys it to thssues, returning in the venous state to the lungs devold of nitrogen and again absorbing it. The tlssues, belng only saturated with nitrogen at atmospherile 